\title{
Research of forecasting method considering demand side resources
}

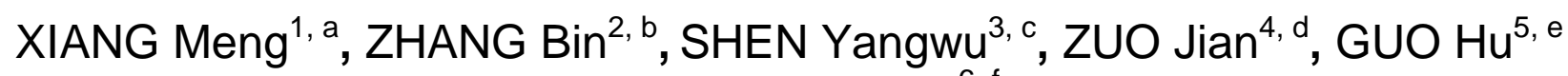 and YU Dongzhen ${ }^{6, f}$}

${ }^{1}$ Electric power research institute, Changsha 410007, Hunan Province, P. R. China

${ }^{2}$ Electric power research institute, Changsha 410007, Hunan Province, P. R. China

${ }^{3}$ Electric power research institute, Changsha 410007, Hunan Province, P. R. China

${ }^{4}$ Electric power research institute, Changsha 410007, Hunan Province, P. R. China

${ }^{5}$ Electric power research institute, Changsha 410007, Hunan Province, P. R. China

${ }^{6}$ Electric power research institute, Changsha 410007, Hunan Province, P. R. China

a489395452@qq.com

\section{Keywords: Demand Response; Energy Efficiency; Flexible load}

Abstract. In this chapter, a load forecasting method considering demand side resources is put forward. This method focuses on the analysis of the influence of demand side resources on load forecasting. By estimating the potential of various types of demand side resources in a certain area .Taking into account the load forecasting process, the load forecasting is more reasonable and accurate. To avoid extensive expansion of investment and waste, Quantitative analysis is carried out by establishing mathematical model. A case study is given to show that the new method can significantly decrease the maximum load of power users, considering the load forecasting method of the demand side resources. Demand side resources not only to reduce user costs, at the same time, it also improves the level of power supply reliability of the system.

\section{Introduction}

In recent years, with the continuous improvement of relevant policies, technical level, the demand side of the resources has aroused widespread attention, Demand side resources in some areas more and more play the role of supply side resources. Abroad, In the United States, energy efficiency resources and demand response resources have been widely used in power system operation and planning. Through the operation of the power system to call the different needs of response resources, to achieve the balance of supply and demand, to meet the needs of ancillary services and other objectives, The application of demand side resources reduces the cost of power system operation and the transaction cost of the market. In the power system planning, The introduction of energy efficiency resources and demand response resources, Reduce the demand for power generation side and power grid side capacity expansion Reduce the cost of a large number of investment.

Application of demand side resources in power system dispatching operation, mainly in order to implement orderly power management and load management (including electricity price policy and direct load control). In recent years, China has gradually explored the demand side resources into the power system planning model and methods, and has launched a variety of pilot programs. Research results show that the introduction of demand side resources, will significantly reduce the supply side of the supply side of the investment, while saving the land, reduce waste, reduce greenhouse gas emissions and other effects. At home and abroad, The demand side has been studied as a resource in the integrated resource planning and power planning, There is no specific application methods and methods for power grid planning.

Based on the above considerations. In this paper, a new idea is proposed. The demand side resources are considered in the power load forecasting, To solve the problem of power grid planning landing, the cost of power grid investment, low utilization of power grid equipment, To promote power grid planning and investment to lean to the direction of change. 


\section{Main idea}

Through reasonable estimating potential of various types of demand side resources in a substation area, and the potential of load forecasting process is considered, it makes load forecast more accurate, and avoids investment waste by extensive expansion. The basic steps can be summarized as: "subdivide load from top to bottom, superimposed calculate from bottom to top". Specific content as follows:

First, determine the scope of the forecast. Select the power supply area of a certain substation radiation range as the forecast range.

Second, users should be classified. Classifying power user who access on each feeder in substation, generally it can be divided into residential users, industrial users, commercial users and other users.

Third, various users of demand side resources should be identified. Each user may have multiple types of demand side resources at the same time, and various types of demand side resources will have a different impact on user's power consumption or load characteristics. Therefore, it is necessary to fully identify all kinds of users, demand side resources in the process of load forecasting should be considered.

Fourth, effect of various types of users' demand side resources on load during the forecast period should be quantitative analyzed. On the basis of qualitative identification of potential demand side resources, it throughs model construction and data collection and processing technology accordingly, the effect of various kinds of demand side resources to traditional load forecasting value can be gained, so that load forecasting value which considering this type user's demand side resources can be gained. Combined with power grid planning, generally Maximum load value can be forecasted.

Fifth, the maximum load of demand side resources in the forecast area is calculated by the multi layer stacking technique. By using the load rate processing technique, the load forecasting results of the demand side resources are obtained by the layer by layer stack. Load forecasting results considering demand side resources can be gained by overlapping method.

The general idea of this method is shown in Figure 1.

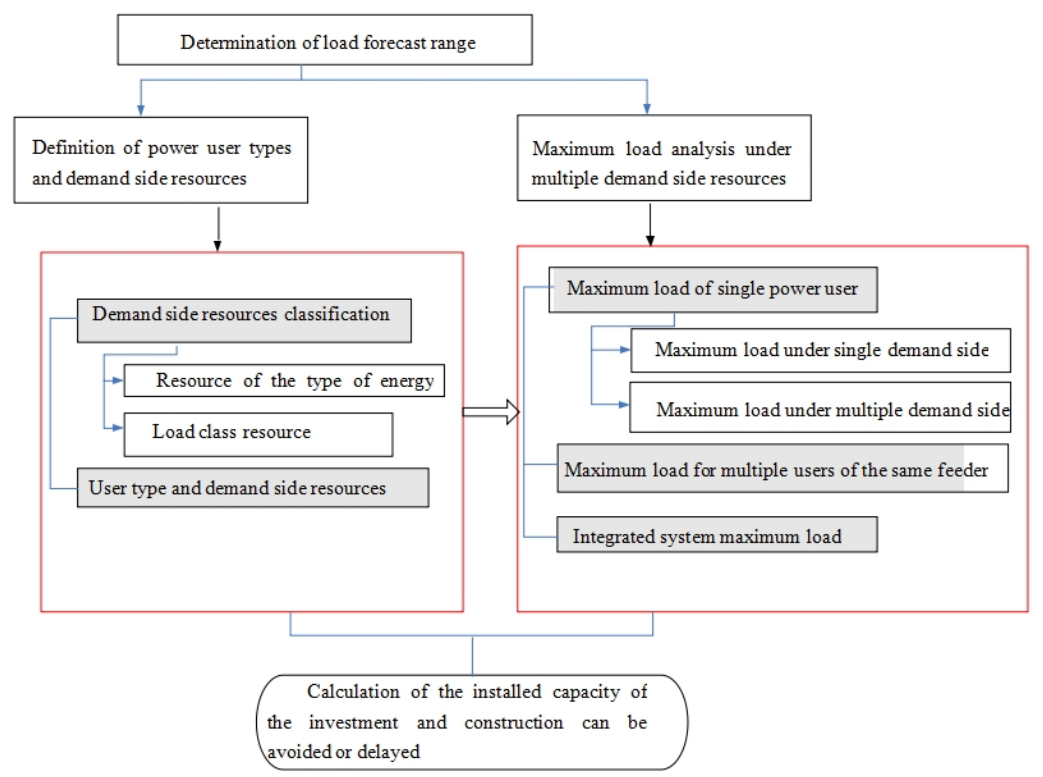

Fig. 1 General idea of load forecasting method considering demand side resources

\section{Model construction}

(1) Demand side resource prediction of the type of multiple load.

After considering various energy efficiency resources, the function of multiple load resources should be considered further. Due to resource saving index load is the load rate, which is a concept 
relative to the overall power supply situation, and it can't allocate to each power link. So, electricity saving potential of the type of load resources should be calculated by its type. Firstly, the calculation formula of the reducing maximum load under the action of a single load resource is:

$$
\begin{aligned}
& \Delta P_{\max , i}= \begin{cases}P_{\max , E E}-Q_{E E} * \lambda_{i} * \frac{1}{\beta_{L D, i} * \frac{1}{t}} & \lambda_{i}=1 \\
0 & \lambda_{i}=0\end{cases} \\
& P_{\max , E E}=\frac{\mathrm{Q}_{E E}}{\beta_{0} * t}
\end{aligned}
$$

In this formula, $\Delta P_{\max , i}$ is the reduced maximum load under the type of i load resources, $\mathrm{kW}$.

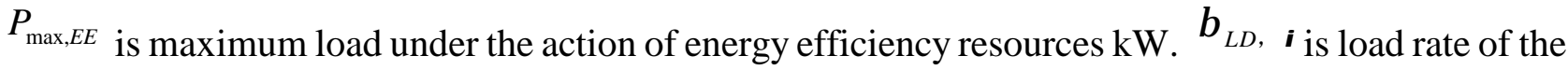
power users under the type of i load resources.

Reduced maximum load under the action of many kinds of load resources is:

$$
\Delta P_{\max }=\left(\Delta P_{\max , 1}+\Delta P_{\max , 2}+\mathrm{L}+\Delta P_{\max , i}+\mathrm{L}+\Delta P_{\max , \text { w }}\right) * \zeta_{1}
$$

In this formula, $w$ is the amount of the type of load resources possessed by user.

Due to load class resources will not play a role at the same time, so the formula (3) introduce load coincidence rate $\zeta_{1}$.

As a result, the maximum load predicted result of the demand side resources is:

$$
P_{\max , D S M}=P_{\max , E E}-\Delta P_{\max }
$$

(2) Load forecasting solution considering demand side resources

Since the substation covers a number of power lines, so when solving the maximum load, power status of each line should be considered, and then use the power superposition, the effect is:

$$
U P_{\max , D S M}=\sum_{i=1}^{n} P_{\max , i}=\left[\sum_{i=1}^{n}\left(\sum_{j=1}^{m} P_{\max , i j}\right) * \zeta_{2}\right] * \zeta_{3}
$$

In this formula, $U P_{\max , D S M}$ is integrated maximum load, $\mathrm{kW} . \zeta_{3}$ is load coincidence rate, which used to adjust the maximum load between different feeders. $n$ is number of lines in the substation.

As a result, variable electric capacity which can be delayed can be calculated by the change of the demand side resources, as shown in the formula (6).

$$
\Delta R=R_{0}-R=\eta *\left(P_{\max , 0}-U P_{\max , D S M}\right)
$$

In this formula, $\Delta R$ is variable electric capacity which can be avoided or delayed to construct after considering demand side resources, kVA.

Details of the calculation process are detailed in the schedule.

\section{Example analysis}

This subject simulates regional electricity in a $220 \mathrm{kV}$ substation, and assuming that all kinds of users are not introduced any demand side resources before the simulation period. On the basis of defining user types on each line, analyzing the main power link of each user, and estimating power saving effect under the type of energy efficiency and load resources, to forecast monthly maximum load whether have demand side resources, and the results were analyzed and compared. 
(1) Basic data

The substation consists of 3 lines, each line covered resident users, industrial users, commercial users and other users. The user's classification and the initial power usage of each line are shown in Table 1:

Table 1 Users and initial power condition

\begin{tabular}{ccccc}
\hline \multirow{2}{*}{ Type of users } & $\begin{array}{c}\text { Number of } \\
\text { users }\end{array}$ & $\begin{array}{c}\text { Initial monthly } \\
\text { electricity } \\
\text { consumption (ten } \\
\text { thousand } \mathbf{k W h})\end{array}$ & $\begin{array}{c}\text { Initial maximum } \\
\text { load }(\text { ten thousand } \\
\mathbf{k W})\end{array}$ \\
\hline Resident users & 25000 & 923.1 & 2.137 \\
\cline { 2 - 5 } Industrial users & Light industry & 14 & 89.2 & 0.206 \\
\hline \multirow{3}{*}{ Business users } & Heavy industry & 12 & 373 & 0.863 \\
\cline { 2 - 5 } & Hotel & 20 & 138.5 & 0.321 \\
\cline { 2 - 5 } & Market & 9 & 175.4 & 0.406 \\
\hline \multirow{3}{*}{ Other users } & Office Building & 18 & 134.6 & 0.312 \\
\cline { 2 - 5 } & Research institutions & 14 & 94.5 & 0.219 \\
\cline { 2 - 5 } & Office & 20 & 152.3 & 0.353 \\
\cline { 2 - 5 } & Hospital & 7 & 138.5 & 0.321 \\
\hline
\end{tabular}

(2) Prediction results

Based on the above basic data and parameter assignment, the power consumption of different users on each line under the demand side in the next 5 years can be obtained by using the maximum load forecasting method considering the demand side resources, As shown in Table 2:

Table 2 Forecast results under demand-side resource Time: Month

\begin{tabular}{cccccc}
\hline \multirow{2}{*}{ User Types } & $\begin{array}{c}\text { The energy } \\
\text { consumption } \\
\text { (million } \mathbf{k W h})\end{array}$ & $\begin{array}{c}\text { The maximum } \\
\text { load efficiency } \\
\text { class (million } \mathbf{k W})\end{array}$ & $\begin{array}{c}\text { The maximum } \\
\text { load load } \\
\text { reduction } \\
\text { (million } \mathbf{k W} \text { ) }\end{array}$ & $\begin{array}{c}\text { The maximum } \\
\text { load demand } \\
\text { side (kW } \\
\text { million) }\end{array}$ \\
\hline \multicolumn{2}{c}{ Resident users } & 1179.734 & 2.731 & 0.473 & 2.447 \\
\hline \multirow{2}{*}{$\begin{array}{c}\text { Industrial } \\
\text { users }\end{array}$} & Light industry & 112.043 & 0.259 & 0.057 & 0.225 \\
\hline \multirow{2}{*}{$\begin{array}{c}\text { Business } \\
\text { users }\end{array}$} & Heavy industry & 508.095 & 1.176 & 0.274 & 1.012 \\
\cline { 2 - 6 } & Hotel & 176.794 & 0.409 & 0.046 & 0.382 \\
\hline \multirow{2}{*}{ Others } & Office Building & 175.831 & 0.407 & 0.066 & 0.476 \\
\cline { 2 - 6 } & $\begin{array}{c}\text { Research } \\
\text { institutions }\end{array}$ & 119.858 & 0.277 & 0.065 & 0.368 \\
\cline { 2 - 6 } & Office & 190.689 & 0.441 & 0.097 & 0.249 \\
\hline
\end{tabular}

(3) comparative analysis

Forecast results of all lines in substation, Comparative analysis of the demand side resources before and after the maximum load forecast. As shown in Table 3: 
Table 3 Comparative analysis of maximum load of demand side resources before and after the action

\begin{tabular}{|c|c|c|c|c|c|}
\hline line number & $\begin{array}{c}\text { The initial } \\
\text { maximum } \\
\text { load (million } \\
\mathbf{k W})\end{array}$ & $\begin{array}{c}\text { The maximum load } \\
\text { forecasting (million } \\
\mathbf{k W} \text { ) } \\
\text { Without } \\
\text { consideration of } \\
\text { demand side } \\
\text { resources }\end{array}$ & $\begin{array}{l}\text { The maximum } \\
\text { load forecasting } \\
\text { (million } \mathrm{kW} \text { ) } \\
\text { Considering the } \\
\text { demand side } \\
\text { resources }\end{array}$ & $\begin{array}{l}\text { Maximum load } \\
\text { reduction ratio }\end{array}$ & $\begin{array}{c}\text { Substation } \\
\text { capacity can } \\
\text { delay the } \\
\text { construction } \\
\text { (million kVA) }\end{array}$ \\
\hline 1 & 3.082 & 4.379 & 3.544 & $23.56 \%$ & \multirow{3}{*}{1.524} \\
\hline 2 & 3.147 & 4.470 & 3.487 & $28.19 \%$ & \\
\hline 3 & 3.240 & 4.839 & 3.775 & $28.18 \%$ & \\
\hline
\end{tabular}

From the table we can see that there is no demand side in the comparative analysis of resources, the demand side resources under the action of the three lines on the maximum load of electricity users showed a significant downward trend, the proportion reached more than $20 \%$. Moreover, the capacity of the substation can be delayed for $15240 \mathrm{kVA}$. It can be known that the demand side resources not only bring the user cost reduction, but also improve the system power supply reliability level.

Case study analysis proves that the new method of load forecasting considering demand side resources can significantly decrease the maximum load of power users, and decrease the rate of $20 \%$, which can delay the substation capacity of $15240 \mathrm{kVA}$. Obviously, the demand side resources not only bring the user cost reduction, but also improve the system power supply reliability level.

\section{Conclusions}

Generally speaking, the basic idea of demand response function for renewable energy grid: through various means of demand side response, effect of controllable load, making virtual turbine generators, assist the traditional regulated load balance, to achieve the full use of water and electricity and distributed energy, promote renewable energy to large scale grid, At the same time to promote inter provincial large scale optimal allocation of resources, realize the optimization of energy structure and energy saving and emission reduction. The role of demand side response to the grid connection of renewable energy is mainly reflected in the change of the nature of the local load. The traditional power system, the load that is not controllable resources, which is exactly equal to the thermal power and hydropower and inter provincial power generation and power generation side, this system is in a passive state is very strong, causing a certain degree of power system and the high cost of renewable energy grid problems.

As a result, the demand side response controllable resources fully scheduling electricity side, the load has a certain adjustable space, effective supply of renewable energy with the uncertainty of the maximum output curve fitting of renewable energy, renewable energy consumption and promote grid. Demand side response can play its potential role depends largely on the residents' participation, and the need to fully consider the characteristics of demand side resource utilization and response law, can be effective to a very good role in promoting the use of renewable energy.

\section{References}

[1] KEANE A,TUOHY A,MEIBOM P, et al. Demand side resource operation on the Irish Power System with high wind power pe-netration[J]. Energy Policy, 2011, 39(5):2925-2934.

[2] JIA Wenzhao, KANG Chongqing, CHEN Qixin. Analysis on demand-side interactive response capability for power system dis-patch in a smart grid framework [J]. Electric Power Systems Re-search, 2012, 90:11-17.

[3] JAMSHID A, MOHAMMAD-IMAN A. Demand response in smart electricity grids equipped with renewable energy sources: a review [J]. Renewable and Sustainable Energy Reviews, 2013, 18 (2):64-72. 
[4] MARMAN M, KAMEL F. Demand side response to mitigate electrical peak demand in Eastern and Southern Australia [J]. Energy Procedia, 2011, 12:133-142.

[5] KARANGELOS E, BOUFFARD F. Towards full integration of demand-side resources in joint forward energy / reserve electricity markets [J]. IEEE Transactions on Power Systems, 2012, 27(1):280-289.

[6] PEDRASA M, SPOONER T D, MACGILL I F. Scheduling of demand side resources using binary particle swarm optimization [J].IEEE Transactions on Power Systems, 2009, 24(3):1173-1181.

[7] RAMANATHAN B, VITTAL V. A framework for evaluation of advanced direct load control with minimum disruption [J]. IEEE Transactions on Power Systems, 2008, 23(4):1681-1688.

[8] PALENSKY P, DIETRICH D. Demand side management: demand response, intelligent energy systems, and smart loads [J]. IEEE Transactions on Industrial Informatics, 2011, 7(3):381-388.

[9]LONG Hongyu, MA Jianwei, WU Kai, et al. Energy conservation dispatch of power grid with mass cogeneration and wind tur-bines [J]. Electric Power Automation Equipment, 2011, 31 (11):18-22.

[10]LIANG Tiantian, GAO Ciwei, WANG Beibei. Applications of demand side management in smart grid [J]. Electric Power Automation Equipment, 2012, 32(5):81-85.

[11]XU Minjie, WU Junyong, HU Zhaoguang, et al. Multi-agent based multi-objective network planning in power market environment [J]. Electric Power Automation Equipment, 2008, 28(1):33-37.

[12]DING Wei, HU Zhaoguang. Intelligent engineering theory expanding and its application in transmission planning [J]. Proceedings of the CSEE, 2008, 28(16):15-21.

[13]ZHOU Jinghong, HU Zhaoguang, TIAN Jianwei, et al. A power integrated resource strategic planning model and its application [J]. Automation of Electric Power Systems, 2010, 34(11):19-22.

[14]TIAN Jianwei, HU Zhaoguang, ZHOU Jinghong, et al. Smart transmission grid expansion planning considering demand response resource $[\mathrm{J}]$. Automation of Electric Power Systems, 2012, 36(10):45-50.

[15]WANG Beibei, LI Yang. Demand side management planning and implementation mechanism for smart grid [J]. Electric Power Automation Equipment, 2010, 30(12):19-24. 